\title{
ANALYSIS AND PROCEDURE OF CALCULATION OF SERIES CONNECTION ELECTRONIC DEVICES FOR CONTACTLESS ARC EXCITATION
}

\author{
N.M. MAKHLIN ${ }^{1}$ and A.E. KOROTYNSKY ${ }^{2}$ \\ ${ }^{1} \mathrm{SE}$ «PWI NRDC for Welding and Quality Control in the Field of Nuclear-Power Engineering of Ukraine» \\ 11 Bozhenko Str., 03680, Kiev, Ukraine. E-mail: electro@paton.kiev.ua \\ ${ }^{2}$ E.O. Paton Electric Welding Institute, NASU \\ 11 Bozhenko Str., 03680, Kiev, Ukraine. E-mail: office@paton.kiev.ua
}

\begin{abstract}
Considered are the issues from analysis of formation of high-voltage pulses, injected into interelectrode gap for initial arc ignition and its re-ignitions, in electronic devices with independent power supply and series connection to electric circuit of main or pilot arc, where all the elements of forming circuit are also connected in-series. The analysis of oscillating processes in the forming circuit is carried out using the solution of known linear differential equations of second degree with non-zero initial conditions. Engineering procedure based on these solutions was proposed for calculation of all components of the forming circuit in electronic devices with independent power supply for arc excitation, as well as recommendations on selection of their element base were given arising from the experimental data and experience of designing, industrial manufacture and operation of such devices. Variants of circuit solutions for oscillating constituent of electronic arc exciters with independent power supply and devices for control of switching cell of the forming circuit were described. 34 Ref., 6 Figures.
\end{abstract}

Ke $\boldsymbol{y} \boldsymbol{w} \boldsymbol{o r d} \boldsymbol{s}:$ arc and plasma welding, initial arc excitation, arc re-ignitions, electronic arc exciters, spark discharge, in-series connection, pulse-phase control

Initial ignition of arc is an important stage of arc and plasma welding cycles, having significant effect on effectiveness and efficiency of these processes and quality of welded joints. A method of arc initiation by means of electric breakdown of interelectode gap with the help of boost devices generating high-voltage pulses [1-4] has the highest distribution among various methods of contactless excitation.

Spark-gap generators of high-frequency pulses (oscillators) were used in a course of many years as boost devices for arc ignition (arc exciters). A lot of works, results of which generalized in [2-6], were dedicated to their investigations, theory and procedure of calculation and designing. Simple structure and relatively small price should be referred to oscillator advantages. Its disadvantages are complexity of control of beginning of high-voltage pulse generation, quick attenuation of high-frequency oscillation due to losses in spark discharger, which requires periodic regulation and maintenance during operation, as well as low values of parameters of electromagnetic compatibility with electron and electric assemblies and devices of welding equipment due to high degrees of radio interferences generated by oscillator in a wide frequency range [3, 5-9].
Beginning of industrial manufacture of power semi-conductors (thyristors, symistors) with high switching and dynamic characteristics provides for the backgrounds of development of sparkless exciters and stabilizers of welding arc free from the disadvantages typical for the oscillators [3, 6, 10-13].

In recent years, series of manufacturers of welding equipment (for example, KEMPPI) begin to use power high-voltage IGBT-transistors as switching units for oscillating circuits of arc exciters. Semi-conductor exciters and stabilizers of arc start to dominate from the beginning of 1970s and today have virtually replaced the oscillators.

Semi-conductor exciters and stabilizers of arc with in-series connection to arc circuit gained the widest application. They favorably differ from devices with parallel connection by higher efficiency, simpleness of protection of welding power sources and other assemblies and devices of welding equipment from influence of high-voltage pulses and better electromagnetic compatibility [3, 6, 9]. Figure 1 shows the circuits of in-series connection of arc exciters to the circuits of main and pilot arc of units for arc, plasma and microplasma welding, plasma and air-plasma cutting of metals, as well as welding, surfacing and spraying using plasmatrons without interelectrode insert. 
Electron (semi-conductor) exciters and stabilizers of arc can be divided into two groups on structure of oscillating constituent.

The first one includes the devices, in which formation of high voltage in the energy storage (mainly capacitive one) is performed with the help of voltage multiplier or by means of resonant pumping.

Switching semi-conductor cell in the devices of the first group has in the most cases parallel connection to in-series connection of induction $L$ and capacity $C$ of forming circuit oscillating constituent. Devices of this group are characterized by versatility according to kind of source voltage. They can have direct supply from the arc voltage, that allows performing automatic connection of the devices during supply of open-circuit voltage to the arc gap and automatic termination of generation of high-voltage pulses or change from mode of initial ignition to mode of stabilization after arc excitation [3, 6].

However, on practice, regardless indicated advantages of the first group devices, electronic exciters and stabilizers of the second group are more widespread. These are the devices with independent power supply (as a rule from alternating current main of industrial frequency), in which switching semi-conductor cell and reaction elements $L$ and $C$ have in-series connection [3, 11, 12].

Formation of high-voltage output pulses injected into the arc circuit from the device, circuit of which is shown in Figure 2, $a$, is performed due to transient process, having place at periodic connections (with double frequency of source voltage) of semi-conductor cell $K$ with doublesided conductivity, based on symictor or two thyristors of back-to-back connection.

Since the transient processes in magnetic conductor of the pulse transformer $T V 1$ (see $\mathrm{Fi}$ gure $2, a$ ) are not linear and $L=f(i)$, strict
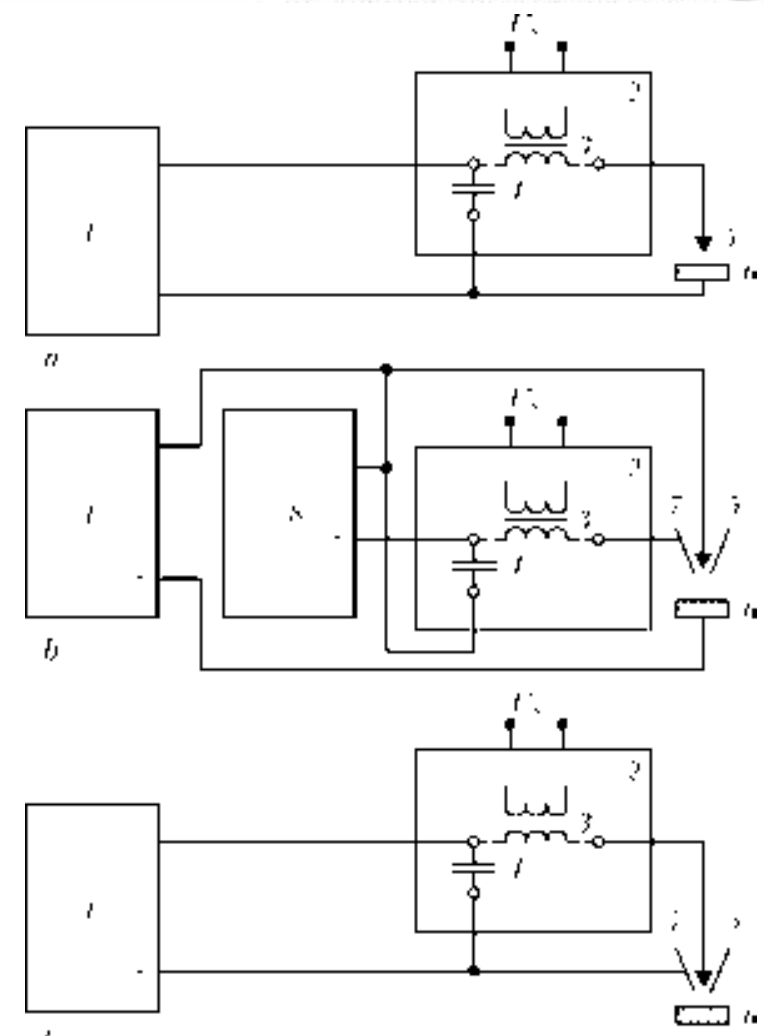

Figure 1. Circuits of in-series connection of arc exciters and stabilizers: $a$ - to main arc circuit in arc welding machines; $b$ - to pilot arc circuit in machines for plasma (microplasma) welding and surfacing, plasma and air-plasma cutting of metals; $c$ - to main arc circuit in machines for plasma welding, surfacing and spraying with the help of plasmatrons without interelectrode insert; 1 - power supply unit of main arc; 2 - arc exciter; 3 - output pulse transformer of arc exciter; 4 - protective (blocking) condenser; 5 - electrode; 6 - part being welded; $7-$ plasmatron nozzle; 8 - power supply unit of pilot arc

analysis of the transient process in the equivalent circuit (Figure 2,b) is difficult due to insufficient cleanness of the results and complexity of computations requiring solution of the system of non-linear differential equations. Therefore, in order to analyse of this equivalent circuit with small error it is relevant to assume the following assumptions:

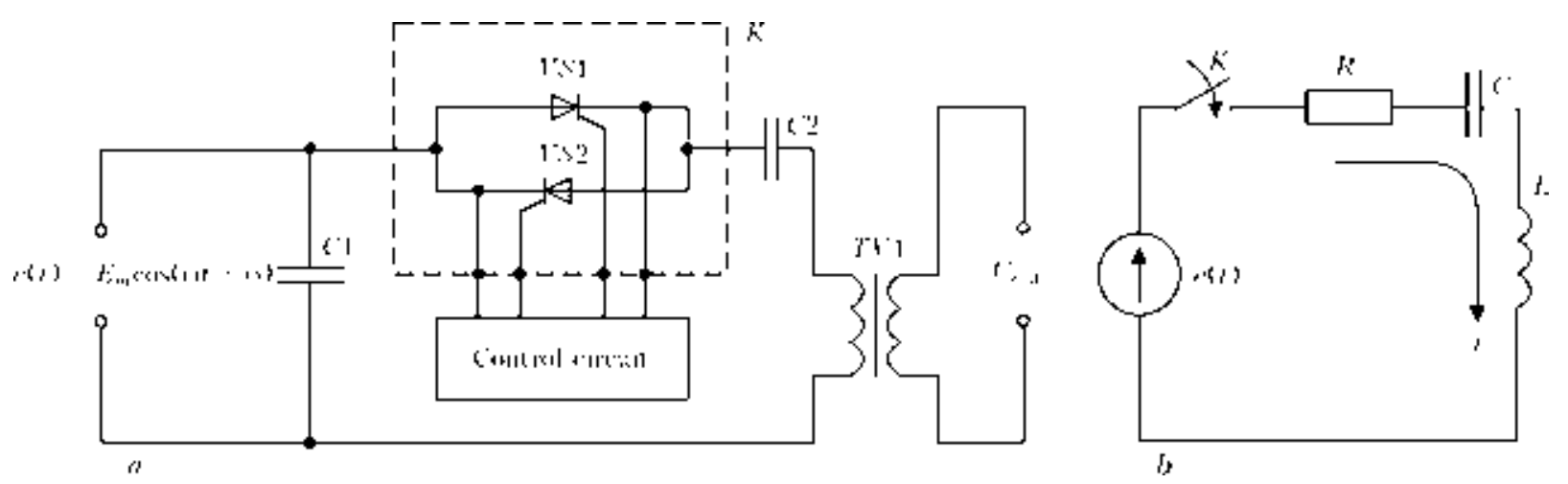

Figure 2. Basic variant of construction of arc exciters and stabilizers with independent power supply and in-series connection to switching cell and elements of forming circuit: $a-$ simplified electric circuit of oscillating constituent; $b$ - equivalent (calculation) circuit of oscillating constituent 
1) $R=R_{K \text { dyn }}+E S R_{C 1}+E S R_{C 2}+R_{L}+R_{\text {c.c }}$, where $R_{K}$ dyn is the dynamic resistance of switched cell $K ; E S R_{C 1}, E S R_{C 2}$ are the equivalent series active resistances of capacitors $C 1$ and $C 2$, respectively; $R_{L}$ is the real resistance of primary winding of pulse transformer $T V 1 ; R_{\text {c.c }}$ is the active resistance of connecting cables;

2 ) induction $L$ of the primary winding of pulse transformer $T V 1$ is linear and equals initial one, and does not depend on current passing in it;

3) $C 1>C 2$, from which $C \approx C 2$;

4) $\tau_{\text {trans }}<T / 2$, where $\tau_{\text {trans }}$ is the duration of transient process; $T / 2$ is the duration of semiperiod of AC input voltage (source voltage);

5) $R / 2 L<1 / \sqrt{L C}$;

6) $e(t)=E_{m} \cos (\omega t+\varphi)=E_{m} \sin [\omega t+$ $+(\pi / 2-\varphi)]$, where $E_{m}$ is the amplitude of AC input voltage; $\omega$ is the its angular frequency and initial phase of this voltage (turn-on angle of semiconductor cell $K$ );

7) $U_{\text {out }}=U_{L} W_{2} / W_{2}$, where $U_{\text {out }}$ is the device output voltage; $U_{L}$ is the induction voltage $L$; $W_{1}, W_{2}$ is the number of winds of primary and secondary windings of pulse transformer $T V 1$, respectively.

Considering assumptions taken for calculation circuit (see Figure 2,b), the transient process at non-zero initial conditions in $R C L$-circuit with charged capacity is described using well-known differential equation of the second order for $C$ capacity voltage $U_{C}[14,15]$ :

$$
L C \frac{d^{2} U_{C}}{d t^{2}}+R C \frac{d C_{C}}{d t}+U_{C}=E_{m} \cos (\omega t+\varphi) .
$$

Voltage $U_{C}$ is the sum of two constituents, namely $U_{C \text { st }}$ became stationary on capacity $C$ after attenuation of transient process, and $U_{C . f}$ voltage being the free attenuation constituent. Stationary voltage $U_{C \text {.st }}$ is determined by particular solution of equation (1) at $t \rightarrow \infty$, i.e. when $d U_{C} / d_{t}=0$ and static current $i(t)=0$, according to which

$$
U_{C . s t}=U_{C_{0}}=E_{m} \frac{X_{C}}{Z} \cos (\omega t+\varphi-\gamma),
$$

where

$$
\begin{aligned}
X_{C}=1 / \omega C ; \quad Z & \left.=\sqrt{R^{2}+(\omega L-1 / \omega C}\right)^{2} ; \\
\operatorname{tg} \gamma & =\frac{R}{\omega L-1 / \omega C} .
\end{aligned}
$$

The free constituent of attenuating oscillations $U_{C . f}$ is described by total solution of homogeneous equation

$$
\frac{d^{2} U_{C . \mathrm{f}}}{d t^{2}}+\frac{R}{L} \frac{d U_{C . \mathrm{f}}}{d t}+\frac{1}{L C} U_{C . \mathrm{f}}=0 .
$$

For $R / 2 L=\delta, 1 / L C=\beta_{0}^{2}$ and $\beta=\sqrt{\beta_{0}^{2}-\delta^{2}}$ designations and assumption $\beta_{0}^{2}>\delta^{2}$, the solutions of equations (1) and (2) can be represented in the form

$$
\begin{gathered}
U_{C}=U_{C . s t}+U_{C . f}=E_{m} \frac{X_{C}}{Z} \cos (\omega t+\varphi+\gamma)+ \\
+e^{-\delta t}\left\{E_{m} \frac{X_{C}}{Z}[\cos (\omega t+\varphi+\gamma)-\cos (\varphi+\gamma)] \times\right. \\
\left.\times \frac{\beta_{0}}{\beta} \sin (\beta t+\gamma)+E_{m} \frac{X_{C}}{Z} \sin \frac{\omega}{\beta} \sin \beta t\right\} \\
i=\frac{E_{m}}{Z} \sin (\omega t+\varphi-\gamma)+\frac{E_{m}}{Z} e^{-\delta t} \times \\
\times\left[\frac{\beta_{0}^{2}}{\omega \beta} \cos (\varphi-\gamma)+\frac{\delta}{\beta} \sin (\varphi-\gamma)-\sin (\varphi-\gamma) \cos \beta t\right] .
\end{gathered}
$$

It follows from (3) that $C$ capacity, overvoltage which 3.2 time exceeds $E_{m}$ value, takes place during connection of switching cell $K$ at the moment, when $e(t)$ achieves the maximum being in antiphase with $C$ charged capacity voltage, i.e. at $e(t)=E_{m}, \varphi=-\gamma, U_{C_{0}}=-E_{m}$.

Considering relationship $U_{L}=L \frac{d i}{d t}, L$ induction voltage is determined using expression

$$
\begin{aligned}
U_{L} & =E_{m} \frac{X_{L}}{Z}\left\{\cos (\omega t+\varphi-\gamma)-\frac{\delta}{\omega} e^{-\delta t} \times\right. \\
& \times\left[\frac{\beta_{0}^{2}}{\beta} \cos (\varphi-\gamma)+\frac{\delta}{\beta} \sin (\varphi-\gamma)-\right.
\end{aligned}
$$

$-\sin (\varphi-\gamma) \cos (\beta t+\beta) \sin (\varphi-\gamma) \sin \beta t]\}$,

where $X_{L}=\omega L$.

In (3)-(5) $\beta$ is the oscillation angular frequency during transient process in $R C L$-circuit; $\delta$ is the coefficient of their attenuation.

Since resistance of the interelectrode gap is sufficiently high (from several tens to hundred of kiloohms) during breakdown and spark discharge, which are referred to the independent unsteady discharges in the gases, then it could be assumed that expressions (3)-(5) are true for open-circuit mode of arc exciter, as well as spark discharge (up to the moment of transfer of spark discharge in the interelectrode gap into stationary arc discharge). At that, the effect of welding circuit, including secondary circuits of boost device, on parameters of elements of arc exciter oscillatory constituent is negligibly small. 
Expressions (3) $-(5)$ and results of the experimental investigations and many years of experience of development, serial production and operation of exciters and stabilizers of arc of in-series connection can be used for calculation of parameters and selection of components for basic variant of similar devices.

Condenser $C 1$ (see Figure 2, $a$ ) is chosen from the condition $C 1>(2-4) C 2$, frequency properties which should correspond to index $\beta$ in (3)(5), ERS value (not more than $10 \mathrm{mOhm}$ ), allowable value of $I_{R . M . S}$ variable component of current through the condenser and $U_{\mathrm{VAC}}$ al allowable effective value of AC voltage on this condenser depending on the biggest value of input voltage (source voltage) $U_{\mathrm{s}}$.

Usually, $C 1=4-6 \mu \mathrm{F}$ at $U_{\text {s.nom }}=380 \mathrm{~V}$, and 6-15 $\mu \mathrm{F}$ at $U_{\text {s.nom }}=220 \mathrm{~V}$, respectively, $I_{R . M . S}$ values, determined from relationship $I_{R . M . S}=$ $=E_{m} / X_{C 1}\left(\right.$ where $\left.X_{C 1}=\omega_{C 1}\right)$ make 0.74-1.11 and $0.68-1.08 \mathrm{~A}$ and $U_{\mathrm{VAC}}$ al value being 600 and $250 \mathrm{~V}$, correspondingly $\left(\right.$ at $U_{\mathrm{s}}=$ $\left.=1.1 U_{\text {s.nom }}\right)$.

Metal-film condensers with polypropylene or polycarbonate dielectric, in particular, condensers of K75-15, K75-24 series, or PHC, PWM or PMB series of ICEL company or similar one of other company-manufacturers, are the most suitable for application as condenser $C 1$ based on combination of characteristics (including frequency ones) and parameters . Values of ERS do not exceed $3.5 \mathrm{mOhm}$ and allowable values of $I_{R . M . S}$ make not less than 9 A [16] in such condensers at the indicated range of their capacities and voltages $U_{\mathrm{VAC} \text { al }}$. From point of view of optimum thermal mode and indices of safety, good results could be achieved at dissipative (parallel) connection of two or three such condensers of corresponding capacity.

Capacity of condenser $C 2$ (see Figure 2,a) can be determined based on necessary value of energy of pulses injected in the arc circuit using relationship $W_{i}=C U_{C 2}^{2} / 2$ (where $W_{i}$ is the pulse energy, $U_{C 2}$ is the condenser $C 2$ voltage in the moment of switching cell connection), i.e. at $t(0)$. Since such cell connection is symmetric in each semi-period of input voltage (source voltage), then $C 2$ condenser voltage is determined as $U_{C 2}=k_{\min } 2 E_{m} \sin \varphi$ (where $k_{\min }$ is the coefficient considering the smallest value of $E_{m}$ in oscillation of input voltage). As a rule, $k_{\min } \geq$ $\geq 0.85$. Based on this, the expression for $C 2$ condenser capacity can be represented as

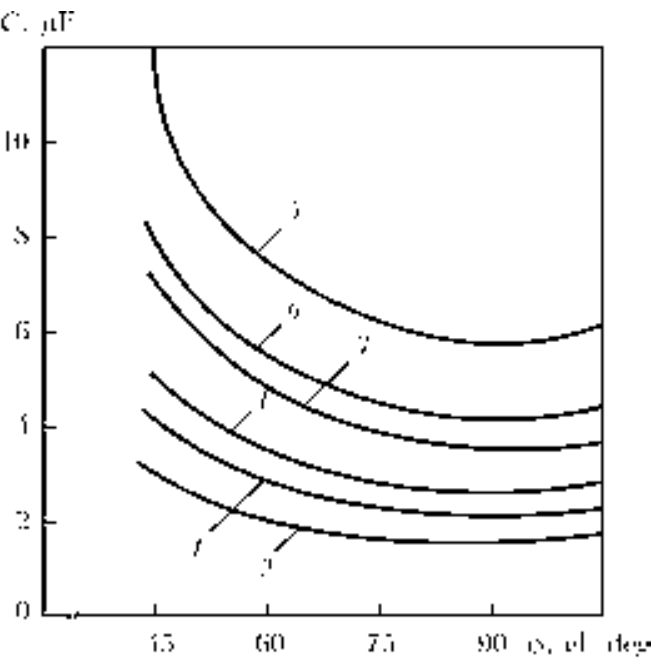

Figure 3. Dependence of capacity $C$ on turn-on angle of cell $K$ of forming $R C L$-circuit at pulse energy of $0.3,0.5$ and $0.8 \mathrm{~J}$, respectively, and effective value of source voltage of $187(1,3,5)$ and $220(2,4,6) \mathrm{V}$

$$
C=\frac{2 W_{i}}{U_{C 2}^{2}}=\frac{W_{i}}{2\left(k_{\min } E_{m} \sin \varphi\right)^{2}} .
$$

According to the earlier investigations and experimental data, providing of effective arc excitation in DC units with single-phase rectification requires $(90 \pm 5)$ el. deg turn-on angle of switching cell (angle $\varphi$ ), that in units with three-phase rectification should be $(90 \pm 10) \mathrm{el}$. deg, and angle $\varphi$ in the AC units makes $(75 \pm 5)$ el. deg $[3,6,11,12]$ based on that $\sin \varphi=(0.94-1)$. As it is seen from Figure 3, C2 condenser capacity should be from 2 to $6 \mu \mathrm{F}$ at reduced $\left(U_{\mathrm{s}}=\right.$ $\left.=0.85 U_{\text {s.nom }}\right)$ and nominal $\left(U_{\text {s.nom }}=220 \mathrm{~V}\right)$ values of source voltage and pulse energy from $0.3^{-}$ $0.8 \mathrm{~J}$, and it should be from 0.5 to $2.0 \mu \mathrm{F}$ at $U_{\mathrm{s}}=$ $=0.85 \cdot 380 \mathrm{~V}$, according to (6). Considering that the transient process in $R C L$-circuit (see $\mathrm{Fi}$ gure $2, b$ ) is accompanied by determined (3) condenser $C 2$ overvoltage (see Figure 2, $a$ ), the allowable amplitude value of DC voltage of this condenser is taken from the condition

$$
U_{V D C \max } \geq 3.2 E_{m} .
$$

The requirements to frequency properties and $E S R$ of condenser $C 2$ are similar to the requirements to condenser $C 1$. Dissipative (parallel) circuit of connection of two-four frequency metalfilm condensers, for example, K75-24 series or ICEL PPA, PWM or PMB series [16, 17], are also relevant for $C 2$.

Values of the active resistance $R$ (see Figure 2, $b$ ) of forming $R C L$-circuit are determined using the reference data given, for example, in [16-18]. In the most cases, ESR of one metal-film condenser with polypropylene dielectric and $U_{V D C \text { max }}=1000-2000 \mathrm{~V}$ do not exceed $4 \mathrm{mOhm}$, 
and $R_{K \text { dyn }}$ values for number of thyristors of domestic and foreign manufacture, including low-voltage thyristors of unified series T122-25T141-40, lie in 3.3-11.0 mOhm range. Sum of active resistances $R_{\text {c.c }}$ of the wires, connecting components of oscillatory constituent of arc exciter, and resistance $R_{L}$ of the primary winding of pulse transformer do not exceed $12 \mathrm{mOhm}$. Respectively, the value of active resistance of the forming $R C L$-circuit makes not more than $40 \mathrm{mOhm}$.

Induction $L$ of the forming $R C L$-circuit (see Figure $2, b$ ) should meet a series of requirements. The most significant from them lie in the fact that providing of oscillatory character of the transition process at $K$ cell turn-on requires fulfillment of necessary condition $2 \sqrt{L / C}>R$ (in semi-conductor exciters and stabilizers of arc this condition is fulfilled virtually in any case), and no-fault operation of semi-conductor cell $K$ demands having $L$ value so that $I_{m}<<I_{\mathrm{TRM}}$ and $(d i / d t)_{K}<\left(d i_{0 .-\mathrm{s}} / d t\right)_{\text {cr }}$ (where $I_{m}$ is the maximum amplitude value in the forming $R C L$-circuit; $I_{\mathrm{TRM}}$ is the maximum allowable repetitive on-state current of cell $K$; $(d i / d t)_{K}$ is the maximum value of rate of current rise in the forming $R C L$-circuit; $\left(d i_{\text {o.-s }} / d t\right)_{\text {cr }}$ is the value of critical rate of current rise of on-state cell $K$ ).

Considering that period of sine source voltage (supply main voltage) significantly (not less that by order) exceeds the duration of transient process in the forming $R C L$-circuit, and after performance of some simplification of expression (4), omitting constituents having insignificant influence on final result, the expression for transient current passing in $R C L$-circuit can be represented in the form

$$
i=\frac{E_{m}}{\beta L} e^{-\delta t} \sin \beta t .
$$

According to (8) the biggest amplitude value of current in the forming $R C L$-circuit can be determined on relationship

$$
I_{m}=\frac{E_{m}}{\beta_{0} L}=E_{m} \sqrt{\frac{C}{L}},
$$

and the maximum value of rate of current rise in this circuit is made on expression

$$
(d i / d t)_{K}=4 I_{m} \beta_{0}=\frac{4 I_{m}}{\sqrt{L C}} .
$$

Calculations and experience of development and designing of arc exciters, in which switching cell and elements of the forming circuit have inseries connection, show that induction $L$ makes as a rule around $20 \mathrm{mH}$ at the limitations caused by electromagnetic and structural parameters of ferritic cores of real pulse transformers. Such (or close to this) value of induction $L$ provides for fulfillment of the condition of oscillatory behavior of transient process in the forming $R C L$-circuit, as well as the values $I_{m} \leq 180 \mathrm{~A}$ and $(d i / d t)_{K} \leq 80 \mathrm{~A} / \mu \mathrm{s}$ at supply main voltage $220_{-33}^{+22} \mathrm{~V}$, that is verified by corresponding oscilografic measurements. At typical values of $R$, $C$ and $L$ calculated in accordance with (6)-(10), the frequency $\beta_{0} / 2 \pi$ of own (free) attenuating oscillations in the forming $R C L$-circuit makes $15-20 \mathrm{kHz}$ and relation of frequencies $\beta_{0} / \beta$ are close to one.

High-voltage pulse transformer $T V 1$ (see $\mathrm{Fi}^{-}$ gure $2, a$ ) is the critical and most complex on design unit of arc exciters. The requirements, made to this transformer, are highly controversial [3, 6, 10-12]. First of all, such a transformer with increased dissipation should correspond to the norms and rules of high-voltage transformers construction. Secondly, its mass-and-dimension indices and cost should be noticeably smaller in comparison with the similar indices of all engineering unit. Besides, surface effect caused by high frequency of pulse currents flowing around the transformer windings, the biggest value of arc current passing through secondary winding of the transformer, as well as electromagnetic and structural parameters of serially manufactured in industry ferritic cores, providing calculation (set) $L$ value should be considered during calculation and designing of the transformer.

Number of works, for example [19-25], are dedicated to the theoretical fundamentals, analysis of the processes and procedures of calculation of inductive elements with ferromagnetic cores, including pulse transformers of ultrasonic and high frequencies. Therefore, present work considers only some aspects of simplified calculation and designing of high-voltage pulse transformer (PT) of arc exciters of in-series connection.

Requirements made to PT of arc exciters are caused by idea of performance of their windings with minimum possible number of winds, following from what the number of winds of the primary circuit $W 1$ of such PT makes as a rule 1 or 2 . According to (5) at $e(t)=-E_{m}$ and $\varphi=-\gamma$, the maximum value of primary winding voltage of PT is 2.1 times higher than the $E_{m}$ value, and at reduced $U_{\mathrm{s}}$ makes

$$
U_{L \max }=2.1 k_{\min } \sqrt{2} U_{\mathrm{s}} .
$$


For example, $U_{L \text { max }}=555 \mathrm{~V}$ at $U_{\mathrm{s}}=220 \mathrm{~V}$ and $k_{\min }=0.85$.

Amplitude value of open-circuit voltage of PT secondary winding $\left(U_{\text {out }}\right)$ should correspond to the levels providing breakdown of the interelectrode gap of technologically grounded length, and appearing after that spark discharge, i.e. $U_{\text {out }} \geq U_{\mathrm{br}}$ should be fulfilled (where $U_{\mathrm{br}}$ is the voltage of interelectrode gap static breakdown). Since, up to now there is no theory of arc discharge, explaining all combination of effects, which accompany the processes of interelectrode gap breakdown and arc discharge in it, so entering of analytical expression for $U_{\mathrm{br}}$ in form acceptable for engineering calculations is very complicated. Therefore, experimental data verified by accumulated experience of application of arc exciters [3-7, 10-12] is reasonable for application at determination of necessary $U_{\text {out }}$ value. According to these data $U_{\text {out }}=3-6 \mathrm{kV}$ in the arc exciters of units for arc welding and most units for plasma welding, surfacing and spraying, $U_{\text {out }}=10^{-}$ $12 \mathrm{kV}$ in the arc exciters of units for arc-plasma cutting, and in some cases it equals $16-20 \mathrm{kV}$. Based on this and considering well-known relationship $W_{2}=W_{1} U_{\text {out }} / U_{L \text { max }}$ at $W_{1}=1-2$ winds, the number of winds $W_{2}$ of the secondary PT winding usually makes $9-18$ in the arc exciters of units for arc and plasma welding, surfacing and spraying in inert gas atmosphere, 18-36 in the exciters of pilot arc of units for air-plasma cutting, and 32-48 in the arc exciters of units for $\mathrm{CO}_{2}$ plasma welding.

Influence of the surface effect on sizes of conductors of PT windings is characterized by penetration depth of high-frequency current $D_{\text {pen }}$, which could be determined in millimeters for conductors from copper with sufficient for practice level of accuracy [25]:

$$
D_{\text {pen }}=\frac{75}{\sqrt{\beta_{0} / 2 \pi}} .
$$

According to (12), section area of conductor of the primary winding should be not more than $1.15 \mathrm{~mm}^{2}$, and thickness of rectangular conductor of the secondary winding makes not more than $1.2 \mathrm{~mm}$ for rational application of section of conductors of PT winding at typical values of $\beta_{0}$.

Rectangular strips from soft copper (for example, copper strips with heat-resistant film coating of PMLBN grades on TU 16.K50-088-2006, PMGLBN on TU 16.K50-009-2007 or bare strips of LMM type on GOST 434-78) are reasonable for application as a conductor of PT secondary winding. At that, dimensions of such strips should be chosen considering number of winds of the secondary winding, $D_{\text {pen }}$ value and necessary cross-section area $S_{\text {cr.s. }}$.

Soft manganese-zinc ferrites of 2500NMS1 and 3000NMS1 grades or ferrites from 3S8 material, designed for operation in power magnetic fields, are the most suitable for application as PT core material. The assumptions are made in order to simplify the process of selection and determination of the main parameters and dimensions of PT core. According to them, the value of magnetic induction $B$ is changed symmetrically relatively to zero of characteristics of magnetization, distribution $B$ and magnetic field intensity $H$ are homogeneous, value of magnetic permeability $\mu_{R}$ is constant, i.e. $B / H$ core characteristic is linear. Shell-type transformers received the highest application in the exciters and stabilizers of arc and bar-type PT are rarely used. As a rule, the cores of such PT have $\Pi$ - or E-shaped configuration with rectangular or round shape of section of cores and yokes.

Application of cores of E-shape configuration, for example, E55/28/21 for PT of exciters of pilot arc or E80/38/20 for PT of exciters of main arc, are the most reasonable for minimizing of mass-and-dimension parameters of PT in the exciters of pilot arc and in the exciters of main arc, current of which does not exceed 160 A. Usage of $\Pi$-shaped cores, for example, PK $40 \times 18$ from ferrite $2500 \mathrm{NMS} 1$ or $3000 \mathrm{NMS} 1$ or cores UU $93 / 152 / 16$ from ferrite 3S8, is acceptable in the exciters of main arc, the nominal current of which makes from 160 to $315 \mathrm{~A}$. П-shaped cores having developed window area $A_{W}$, for example, UU $101 / 152 / 30$ or UR $114 / 78 / 38$, are good for PT exciters of arc, the nominal current of which varies from 315 to $500 \mathrm{~A}$, and for PT exciters of arc of machines for $\mathrm{CO}_{2}$ plasma welding.

When selecting the PT core, determination of total effective cross-section of core $A_{E}$ based on specified induction value $L$ of PT primary winding, can be done using relation

$$
L=A_{L} W_{1}^{2},
$$

where $A_{L}$ is the integral parameter, specified in technical data of the core and determining a value of winding induction located in this core, depending on square of its winds (for PT - depending on square of primary winding winds). At that, two approaches are possible. The first one assumes application of single core that requires fulfillment of condition $W_{1} \geq \sqrt{L / A_{L}}$, so that in real PT the number of winds should be not less than 2 and, respectively, $W_{2} \geq 20$. Such an approach is sufficiently suitable in designing 
of PT exciters of pilot arc and limited for PT exciters of main arc, the nominal current of which does not exceed $250 \mathrm{~A}$. According to the second approach, necessary value of $A_{L}$ at set $L$ and $W_{1}$ values is achieved through application in $\mathrm{PT}$ of the core consisting from several single cores, number of which is determined on expression

$$
n_{\mathrm{c}}=\frac{L}{W_{1}^{2} A_{L S}},
$$

where $n_{\mathrm{c}}$ is the rounded upward number of single cores; $A_{L S}$ is the $A_{L}$ parameter of single core. Namely, the second approach is typical for PT exciters of main arc, the nominal current of which makes more than $250 \mathrm{~A}$.

The necessary area of core window $A_{W}$ is determined using standard procedure, given, for example, in [20, 23, 25], through calculation of total area of the window covered by conductors of PT windings considering the thickness of inter-wind and inter-winding insulation and increased temperature of $\mathrm{PT}$ at it cooling due to natural convection.

$A_{E}$ and $A_{W}$ values received with the help of reference data allow performing preliminary selection of standard size of PT core, after what correspondence of electromagnetic mode of chosen core to $B_{\max }<B_{S}$ condition (where $B_{\max }$ is the value of magnetic induction at peak value $H_{\text {max }}$ of magnetic field intensity in the core, and $B_{S}$ is the value of saturation magnetic induction of the core) should be checked.

If, according to the data given [25-27], it is assumed that the maximum allowable value $B_{\max }=0.2 \mathrm{~T}$ and values of relative $\mu_{0}$ and effective $\mu_{\text {ef }}$ magnetic permeability of the core are equal, then for section of $B=f(H)$ curve of places of hysteresis loop of 2500NMS1, 3000NMS1 or 2S8 ferrites, in which $B / H=$ const, the maximum allowable value $H_{\max }$ at core temperature not more than $120{ }^{\circ} \mathrm{C}$ is calculated on expression

$$
H_{\text {max }}=\frac{1.592 \cdot 10^{5}}{\mu_{\mathrm{ef}}} .
$$

Since usually $\mu_{\mathrm{ef}}=(1.70-1.99) \cdot 10^{3}$, then $H_{\max }$ values lie in the ranges $94-80 \mathrm{~A} / \mathrm{m}$.

Besides, $H_{\max }$ values should be determined depending on amplitude value $I_{m}$ wrapping the PT primary winding, number of winds of these winding and size of selected core, using expression

$$
H_{\max }=\frac{I_{m} W_{1}}{l_{\mathrm{ef}} n_{\mathrm{c}}},
$$

where $l_{\text {ef }}$ is the reference value of effective length of magnetic line path. If $H_{\max }$ value, calculated on (16), exceeds the value, received on expression (15), then it is necessary to choose size of the core with larger $l_{\text {ef }}$ or increase $n_{\mathrm{c}}$ of single cores, forming PT core, after what carry out checking calculation again.

Low frequency of passing of pulses of output voltage $U_{\text {out }}$, significant level of transient current and voltage on the elements of circuit forming these pulses and their high relative duration (not less than 10) provide for the relevance of application of low-frequency thyristors as a cell $K$ (see Figure 2, $a$ ) in the arc exciters with independent power supply. They together with high switching capabilities have relatively low values of $R_{K}$ dyn in on-state, control power insignificant in comparison with switching power, high service safety, mass production and application and relatively small cost. The most preferable among such thyristors are the domestic ones of unified series T122-25 or T131-40 at nominal source voltage (supply main voltage) $220 \mathrm{~V}$, and T132-25 or T141-40 series at nominal source voltage $380 \mathrm{~V}$, or their foreign analogues.

Class of thyristors based on repetitive pulse back voltage $U_{\mathrm{RRM}}$ is chosen from the relationship

$$
U_{\mathrm{RRM}}=100+3.2 E_{m} .
$$

Thyristors of the 12th class can be recommended considering (17) at supply main voltage $220 \mathrm{~V}$, and that of the 20th class at $380 \mathrm{~V}$.

The maximum average and active current values, passing through thyristor in its on-state can be determined by means of approximation of exponential bidirectional radiopulse of current $i$, passing in forming $R C L$-circuit, by unidirectional video pulse of rectangular shape. According to this, the maximum average value of current $I_{\mathrm{TAV}}$, passing through thyristor in its on-state, is calculated on expression

$$
I_{\mathrm{TAV}}=0.5 I_{m} \frac{\tau_{\mathrm{p}}}{T_{\mathrm{p}}},
$$

where $\tau_{p}$ is the duration of exponential bidirectional radiopulse of current $i$ (or corresponding to it unidirectional videopulse), determined as $\tau_{\mathrm{p}}=1 / \delta=2 L / R ; T_{\mathrm{p}}$ is the period of frequency of pulse passing, being equal to the period of doubled frequency of power supply voltage of arc exciter. The maximum active $I_{\text {TRMS }}$ value of current passing through the thyristor can be determined from the relationship

$$
I_{\mathrm{TRMS}}=0.5 \frac{I_{m}}{\sqrt{T_{\mathrm{p} / \tau_{\mathrm{p}}}}} .
$$


It follows from (18) and (19) that, for example, the maximum average and active values of current passing through thyristor in its on-state make $I_{\mathrm{TAV}}=9.0$ and $28.5 \mathrm{~A}$, respectively, at given typical values of $R, C, L$ and $I_{m}$. Therefore, in this case, the thyristors of T122-25 series, in which maximum allowable average current is $25 \mathrm{~A}$ and limiting allowable active value of current is $31.4 \mathrm{~A}$ [18], can be used.

Critical rate of current rise $d i_{\text {on }} / d t$ in on-state for low-frequency thyristors of unified series makes not less than $100 \mathrm{~A} / \mu \mathrm{s}$, and, therefore, $(d i / d t)_{K}<d i_{\text {on }} / d t$ requirement for the arc exciters with independent power supply (see Figure $2, a$ ) is fulfilled virtually in any case.

Output impedance of the exciters with in-series connection to arc circuit, mainly depending on induction and effective resistance of PT secondary winding, makes from 1.2 to $9.0 \mathrm{kOhm}$, that predetermines presence of dropping external volt-ampere characteristics in the arc exciters.

Control of turn-on of thyristor switching cell $K$ (see Figure 2, $a$ ) and, respectively, the moments of beginning of output pulse $U_{\text {out }}$ generation, is performed by means of widely distributed synchronous pulse-phase control. It differs by control pulse feed angle, often from phase, corresponding to moments of zero values of supply main voltage. Realization of pulse-phase control can be performed using number of circuit solutions for phase-shifting devices (PSD), designed on such semi-conductor devices as diode, transistors, thyristors or analogues or digital microcircuits, or combination of the first and the second [10, 22, 24, 28]. PSD designed on the basis of unijunctional transistors (double-base diodes) have the widest distribution in the arc exciters with independent power supply. Analysis, calculation procedure and recommendations on selection of double-base diode PSD are given in [28], and Figure 4 shows a typical circuit solution of PSD, applied in the arc exciters with independent power supply. Synchronizing voltage in such PSD is formed with the help of stabilitron tube $V D 2$ and regulation of moment for generation of turn-on pulse of thyristors of arc exciter switching cell is carried out with the help of variable resistor $R 4$. Detailed description of this PSD and voltage diagrams in different points of its circuit are given in [12].

Thyristors of the switching cell $K$ can break down due to exceeding of allowable value of current overloading. It will inevitably happen in the case of saturation of PT core, the secondary winding of which has in-series connection to circuit of DC arc. Therefore, the oscillating constituent

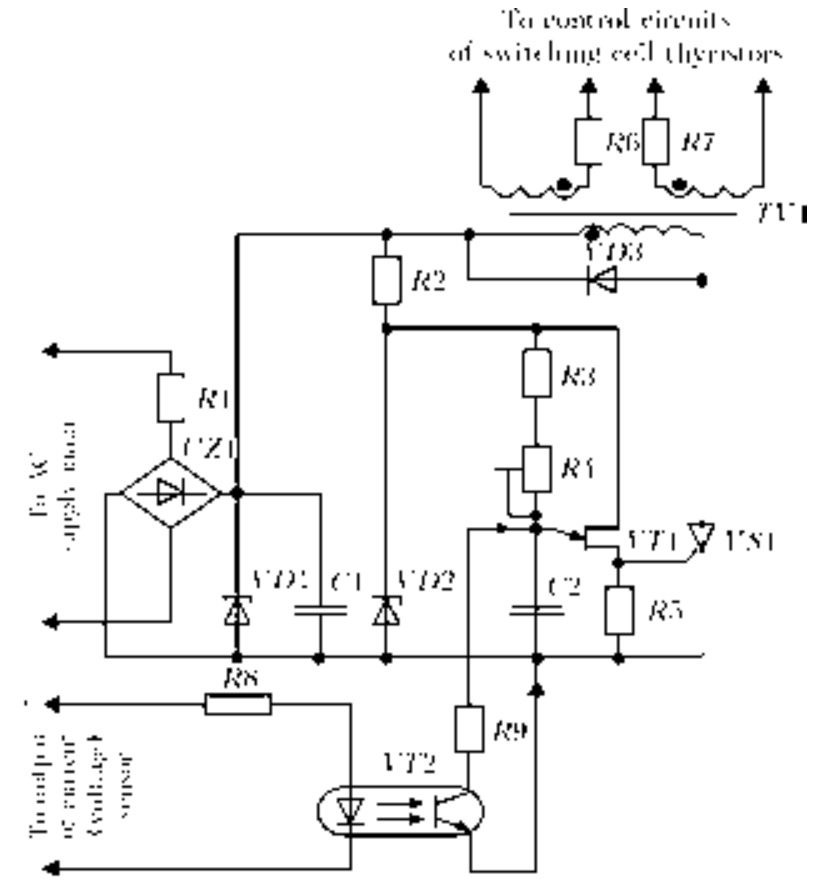

Figure 4. Typical electric schematic of PSD of arc exciters with independent power supply

of arc exciter should automatically switch off during setting into the interelectrode gap of stationary arc discharge. In PSD (see Figure 4) such switch off is carried out with the help of assembly, consisting of fast-operating transistor optical coupler $V T 2$ and current-limiting resistors $R 8$ and $R 9$. Shunting of condenser $C 2$ is provided when signal from the output of arc (voltage) current sensor comes to the input of this assembly. The sensors operating on Hall effect are often used as the sensors of arc current in modern machines and welding power supplies. If such a current sensor is absent in the machine control system, then current shunt set in the arc circuit can be used as an arc current sensor. Figure 5 shows a variant for current sensor construction, including shunt $R S 1$, linear noninverting shunt amplifier based on microcircuit $D A 1$ and comparator unit based on microcircuit $D A 2$.

A signal, level of which is proportional to the arc current, is formed during appearance of cur-

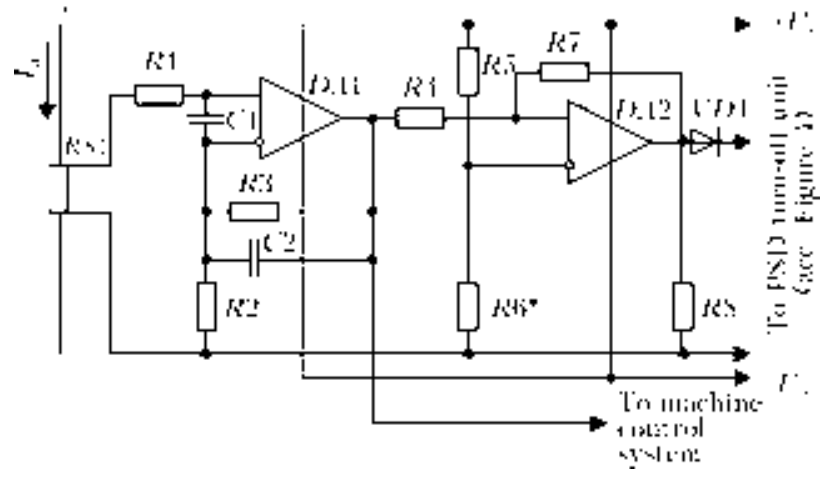

Figure 5. Electric schematic of variant of construction of arc current sensor 

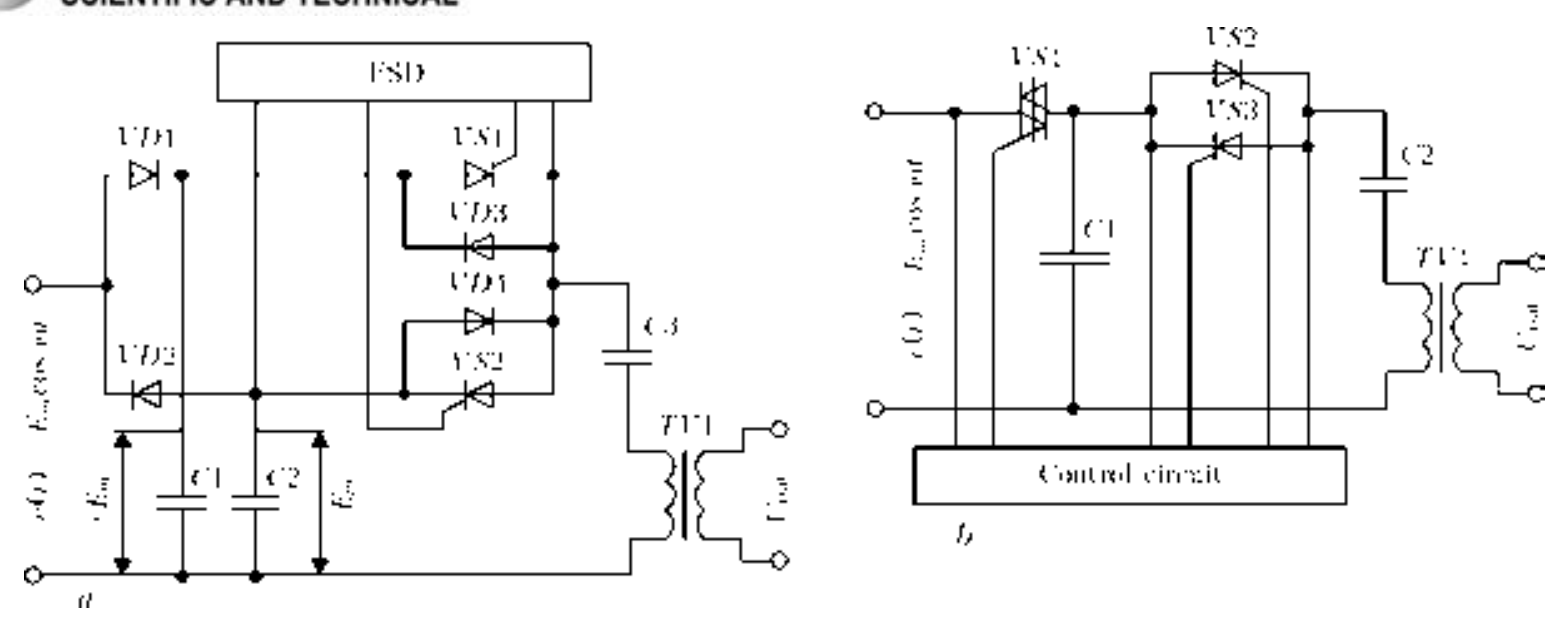

Figure 6. Electric schematic variants of construction of oscillatory constituent in arc exciters with power supply of forming $R C L$-circuit from energy storage devices: $a$ - circuit of arc exciter with double-channel energy storage; $b-$ circuit of device for arc excitation with single-channel energy storage

rent in the arc circuit at the output of microcircuit $D A 1$. This signal is fed into the machine control system and to the input of comparator unit based on microcircuit $D A 2$, operation threshold of which is set with the help of resistor $R 6$. The voltage from the output of comparator unit is fed to the input of PSD turn-off unit (see Figure 4). In the case, when determination of moment of setting of stationary arc discharge in the interelectrode gap is carried out by arc voltage sensor, the signal proportional to this voltage can be fed to the input circuit of comparator unit based on microcircuit DA2 (see Figure 5), i.e. through resistor $R 4$.

The disadvantages of arc exciters with independent power supply designed on basic variant (see Figure 2, $a$ ) are the dependence of amplitude and energy of output pulses on turn-on angle of thyristors of switching cell $K$ and oscillations of source voltages (supply main voltage) as well as the necessity of preliminary regulation (using PSD) of the moments of beginning of output pulse generation, in particular, at excitation and stabilization of AC arc.

Effect of supply voltage fluctuations on parameters of output pulses can be minimized to acceptable level by means of application of reactive elements and $\mathrm{PT}$ in the forming $R C L$-circuit. They are calculated in accordance with given in present work procedure for minimum allowable supply voltage making, as a rule, $85-90 \%$ of nominal values.

Dependence of parameters of output pulses of the arc exciters with independent power supply on the turn-on angle of thyristors of switching cell $K$ can be eliminated due to power supply of forming $R C L$-circuit from energy storage devices (mainly of capacitor type). Figure 6 shows the examples of circuit solutions for such devices.
Condensers $C 1$ and $C 2$ are the energy storage devices in the arc exciter, constructed based on schematic from Figure 6, $a$ [29]. Their charging to the source voltage amplitude value $\pm E_{m}$ (supply main voltage) is carried out through separation diodes $V D 1$ and $V D 2$.

Arc exciters made based on schematic, presented in Figure $6, a$, provide the possibility of generation of output pulse, stabilized on amplitude and energy, virtually at any moment of each semi-period of source voltage. At that, discharge of each storage condensers takes place in those semiperiods of source voltage, when the separation diodes connected to these condensers are in nonconducting state. This provided the possibility of application of the arc exciters, built on circuit given in Figure 6, $a$, as universal devices for preliminary excitation of DC and AC arc as well as for stabilizing (re-ignitions) of $\mathrm{AC}$ arc $[6,12]$.

Charging of the storage condenser $C 1$ in single-channel device, schematic of which is given in Figure 6, $b$ [30], starts in the beginning of each semi-period of source voltage at turning on of thyristor cell with double-side conductivity (symistor) VS1. Symistor VS1 is switched on and condenser $C 1$ is charged till the voltage of $C 1$ condenser achieves the amplitude value of source voltage. Generation of stabilized amplitude and energy output pulse starts from switching of thyristors VS2 and VS3 using the control circuit at any moment of the second part of semiperiod of source voltage, but not earlier then 500-700 $\mu$ s after turn-off symistor VS1. Based on this, area of application of single-channel device (Figure $6, b$ ) is an initial excitation of direct current. On practice such devices are used for striking of pilot arc in the plasmatrons for metal welding and cutting. 
It should be noted that the devices, circuits of which are shown in Figure 6, do not have wide distribution, regardless some advantages, since in comparison with basic variant of construction of arc exciters (see Figure 2, $a$ ), the devices with energy storage units (Figure 6) require larger number of semi-conductor devices and passive elements for their realization, therefore have higher static and dynamic losses, more complex structure and lager price.

Necessity of preliminary regulation or adjustment of turn-on angle of thyristors of switching cell for providing effective initial ignition of the DC arc with the help of arc exciters, made on the circuit shown in Figure 2, $a$, can be eliminated using PSD. It is designed on principle of detection of power supply voltage amplitude. One of the examples of circuit solution for such PSD is given in [31].

PSD, which uses differential method of formation of control pulses for switching cell thyristors and based on generation of these pulses at rapid changes of arc voltage, can be used for elimination of necessity of preliminary regulation or adjustment of moments of beginning of generation of output pulses in exciters and stabilizers of arc universal by current type. Example of construction of such PSD can be a control circuit of exciter-stabilizer of arc VSD-03 UZ, given in [3].

Industrial large-scale production of arc exciters with independent power supply and in-series connection to arc circuit, made in form of separate monolithic devices, was mastered at Ukrainian enterprises for the first time in 1975. More than 25,000 of units of arc exciters of UPD-1, UPD-2 and UPD-3 series and their different modifications were manufactured during 1976-1993. They found wide application as devices for contactless initial arc ignition, as well as stabilizers of AC arcing, including during argon-arc welding of aluminum and its alloys [3, 9, 11, 12, 32-34]. Such arc exciters are used in the machines and units for arc and argon-arc (TIG) welding (in particular, in the machines and units of I-118, I-190, UDG-310M, UKhL4 types), in machines for plasma and microplasma welding, surfacing and spraying (for example, UPS-301, UPS-501, UKhL4, UN-150, «Kiev-7», N-155, UMPDS0605 UKhL4), in the machines for plasma and air-plasma cutting such as «Kiev-4», in gas-cutting machines with program control of «Cristall» type, in the assembly stations for arc and TIG $\mathrm{DC}$ and $\mathrm{AC}$ welding and in other welding equipment of domestic and foreign manufacture.

Due to change of economic conditions in 1991 the volume of domestic manufacture of electronic arc exciters has dramatically reduced, however, today their production is carried out in series of foreign countries (mainly as a constituents of technological units) as well as by small batches in Ukraine and Russia. Works on improvement of such devices continue at that.

\section{Conclusions}

1. Using the solutions of well-known linear differential equations of the second order, the analysis of electromagnetic processes in the circuit of basic variant of construction of electronic arc exciters with independent power supply and in-series connection to arc circuit, which have found the widest distribution among the boost devices for contactless initial arc ignition and arcing stabilization, was performed.

2. Engineering procedure for calculation of such devices was developed based on carried out analysis and considering experience of development, designing, manufacture and operation of the arc exciters with independent power supply and in-series connection to arc circuit.

3. In recent years the electronic arc exciters, which use voltage multiplication and resonant pumping for formation of increased voltage in oscillation component, gain more and more application. At that, semi-conductor switching cell has parallel connection to in-series connection of capacitor storage device and primary winding of output pulse transformer. Analysis and procedure for calculation of such devices require separate study that is not covered in present work.

Authors would like to express their thanks to engineers V.Yu. Buryak, A.G. Skirta and D.S. Oliyanenko for valuable help in preparation of this work.

1. Paton, B.E., Zavadsky, V.A. (1956) Pulse ignition of arc in gas and manual arc welding. Avtomatich. Svarka, 3, 26-35.

2. Goloshubov, V.I. (2005) Welding power supplies. Kiev: Aristej.

3. (1986) Arc welding equipment: Refer. Book. Ed. by V.V. Smirnov. Leningrad: Energoatomizdat.

4. Pentegov, I.V., Dymenko, V.V., Sklifos, V.V. (1994) Welding power supplies with a pulse arc ignition. Avtomatich. Svarka, 7, 36-39.

5. Gufan, R.M. (1967) Study of welding oscillators: Syn. of Thesis for Cand. of Techn. Sci. Degree. Rostov-na-Donu.

6. Temkin, B.Ya. (1981) Theory and calculation of welding arc exciters: Syn. of Thesis for Cand. of Techn. Sci. Degree. Leningrad.

7. Gufan, R.M., Zolotykh, V.G., Budnik, N.M. et al. (1966) Universal welding oscillator ISO. Avtomatich. Svarka, 8, 50-53.

8. Leskov, G.I., Lugin, V.P., Svetlov, A.T. (1976) Suppression of radio interference created by exciters and stabilizers of arc discharge. Ibid., 10, 56-59. 
9. Makhlin, N.M., Fedotenkov, V.G., Livshits, D.M. et al. (1979) Suppression of radio interference created by arc exciters of UPD-1 type. Ibid., 12, 55-57.

10. Lankin, Yu.N., Lapchinsky, V.F., Masalov, Yu.A (1969) Pulse generator for ignition of welding arc. Ibid., 10, 61-63.

11. Dudko, D.A., Fedotenkov, V.G., Makhlin, N.M. (1980) Thyristor pulse generators of UPD-1 type. Ibid., 6, 61-63.

12. Fedotenkov, V.G., Makhlin, N.M., Temkin, B.Ya. (1981) Pulse generator for ignition and stabilization of alternating current arc. Svarochn. Proizvodstvo, 8, 33-34.

13. Paton, B.E., Zaruba, I.I., Dymenko, V.V. et al. (2007) Welding power supplies with a pulse stabilization of arcing. Kiev: Ekotekhnologiya.

14. (2008) Theoretical principles of electrical engineering: Refer. Book on theory of electric circuits. St.-Petersburg: Piter.

15. Levinshtejn, M.L. (1972) Operational calculus in problems of electrical engineering. Leningrad: Energiya.

16. http: / / www.dacpol.com.pl

17. http://www.elcod.spb.ru

18. Zamyatin, V.Ya., Kondratiev, B.V., Petukhov, V.M. (1988) Power semiconductor devices. Thyristors: Refer. Book. Moscow: Radio i Svyaz.

19. Ermolin, N.P. (1969) Calculation of low power transformers. Leningrad: Energiya.

20. Baev, E.F., Fomenko, L.A., Tsymbalyuk, V.S. (1976) Inductive elements with ferromagnetic cores. Moscow: Sov. Radio.

21. Volgov, V.A. (1977) Parts and components of electronics. Moscow: Energiya.

22. Pisarev, A.L., Detkin, L.P. (1975) Control of thyristor transducers. Moscow: Energiya.

23. Zeman, S., Osipov, A., Sandyrev, O. (2007) Specifics of operation of high-frequency transformer in cir- cuit of series-resonant inverter. Silovaya Elektronika, 1, 67-72

24. (2001) Microcircuits for pulse power supplies and their application. 2nd ed. Moscow: Dom DodekaXXI.

25. (1988) Reference book on electrotechnical materials. 3rd ed. Leningrad: Energoatomizdat.

26. http:/ / www.epcos.com

27. (1971) Thyristors (Technical Refer. Book). 2nd ed. Moscow: Energiya.

28. Gottlib, I.M. (2002) Power supplies. Inverters, converters, linear and pulse stabilizers. Ed. by S.A. Luzhansky. Moscow: Postmarket.

29. Shmakov, E.I., Fedotenkov, V.G., Kolesnik, G.F. Device for excitation and stabilization of arcing process. USSR author's cert. 567563. Publ. 1977.

30. Fedotenkov, V.G., Makhlin, N.M., Turchin, P.S. Device for arc excitation. USSR author's cert. 1202768. Publ. 1986.

31. Ivanov, Yu.E., Kozak, V.V., Likhoded, V.P. et al. Device for switching of thyristors. USSR author's cert. 1115174. Int. Cl. N 02 M 1/08. Publ. 1984.

32. Shmakov, E.I., Makhlin, N.M., Fedotenkov, V.G. et al. (1978) Application of alternating current for welding of low-alloyed and alloyed steels, aluminium and its alloys. Montazh. $i$ Spets. Raboty v Stroitelstve, 4, 20-22.

33. Bugaev, P.N., Sidoruk, V.S., Makhlin, N.M. et al. (1986) Application of manual arc welding at modulated current in fabrication and assembly of small diameter pipelines. Montazh. $i$ Spets. Stroit. Raboty. Series 19: Assembly and adjustment of automation and communication means, 11, 26-28.

34. Chigarev, V.V., Granovsky, N.A., Kondrashov, K.A. et al. (2007) Power exciter as a stabilizer of welding arc. Svarochn. Proizvodstvo, 7, 14-16.

Received 15.07.2013 